\title{
CHALLENGES WOMEN FACE IN LEADERSHIP POSITIONS: A QUANTITATIVE APPROACH IN CYCLES' 1 AND 2 SCHOOLS IN OMAN
}

\author{
Hala Said Suleiman Al-Ruhaili ${ }^{1 *}$, Mohamad Johdi Bin Salleh², \\ and Mohd Burhan Bin Ibrahim ${ }^{3}$
}

${ }^{1}$ Ph.D. Candidate at Kulliyyah of Education, International Islamic University Malaysia (IIUM):

hala.alruhili88@gmail.com

${ }^{2}$ Assoc. Prof. Dr., Kulliyyah of Education, International Islamic University Malaysia (IIUM):

johdi@iium.edu.my

${ }^{3}$ Assoc. Prof. Dr., Kulliyyah of Education, International Islamic University Malaysia (IIUM):

mburhan@iium.edu.my

${ }^{*}$ Corresponding Author

\begin{abstract}
This quantitative study explores the challenges that face Omani women in becoming cycle 1 and cycle 2 school principal. The problem is that; Omani women occupy only $9 \%$ of the leadership positions among civil service employees. Oman is ranked 127 th out of 135 countries, and was given a 0.587 score, regarding the women participation in the labor market. The society's perception of women as having weak qualities compared to men, the community looks at women as being emotional and unable to make decisions. This study is implemented in both Cycle 1 and Cycle 2 female schools in four regions: (Al-Batina, Al-Dhahira, AlSharqia and Al-Dakhalia). An online questionnaire with (30) paragraphs has been used as a tool for data collection. Thirty female school principals were the research participants in the current study. (11) from cycle 1 schools and (19) from cycle 2 schools. The findings revealed that: Firstly, the majority of responses confirmed that women have the right and ability to have a job at leadership positions in Oman. Secondly, cultural barriers do not hinder females in becoming school principals. Thirdly, the study revealed that women may receive support from their families to take leadership positions. On the other hand, it detected that the personal challenges such as limited ambition, less motivation as well as less desire to reach leadership positions and the traditional views towards women role in Omani society; have the biggest impact on preventing Omani women to take leadership roles. It is also evident from the study that women are overcoming gender related challenges by taking up education and working hard to be as good as the men in Oman.
\end{abstract}

Keywords: challenges, Omani women, leadership positions.

\section{INTRODUCTION}

The roles of women in the Omani Society before 1970 were as simple as managing the home, taking care of children and cooperating with the conduct of the husband. However, since 1970, Oman has developed significant social, political, economic and educational transformations resulting in the increase in women's participation in establishing leadership roles in the Omani society. Several associations have been set up 
such as the first Omani's Women's Association followed by the Women's Rehabilitation Center. The former was established to encourage women to learn, share experience and to teach fellow women while the latter was set up for the improvement of women's status and training them independence. From then, women have also been permitted to hold leadership positions in the government (Al-Omairi and Amzat, 2012).

However, despite the efforts made to achieve equal rights for women and men in the society, the current literature still shows that there is an underrepresentation of women especially in leadership positions (Schwanke, 2013). The society tends to have the perception that women are getting to the position of equity while the actual sense is that this is far from being achieved.

The scarcity of women leaders appears to be caused by many factors. The common reason for this is the traditional norms linked to women, the beliefs in innate female characteristics and responsibilities and the perception that leadership roles are more fitted to males than females. Also, because of religious and cultural influences, gender inequality and separation has been observed even in Oman's educational system (Reciniello, 2011). The moment a girl can reproduce, she has to be disaggregated from the male and thus, Omani students in Cycle 2 (Grades 5-10) are separated by gender in public schools. Male students are taught by male teachers and female students by female teachers (Alkharusi et al., 2014).

In addition, female schools have female principals as it would not be allowed for a male to be a principal in a female school or vice versa. In Coleman's seminal report, it was shown that such segregation has an impact on the outcome of the student (Coleman, 1966). For instance, school education is segregated based on gender in Oman and female schools are managed by female principals while male schools are managed by male principals. According to the statistics produced by TOSD (2016), the female principals outnumber the male ones as female schools are more than male one. The designation of traditional roles and responsibilities may have a great impact on female's or women's career choice and their preparation to hold leadership positions in the future.

Oman has experienced significant improvements in different fields including education, policies, health, and increasing participation of women in leadership, and promoting modernization, among others (Miller, 2014). However, the females in Oman do not get the same freedom and trust compared to those in the Western countries. The traditional habits of women in Oman hinder them from reaching their full potential even though almost all of them have covered Cycle 1 (Grades $1-4$ ) and Cycle 2 (Grades $5-10$ ) education which is primary and secondary school respectively and even tertiary education. In some cases, parents refuse to allow their daughters to complete higher education and most families only consider women as mere mothers and housekeepers to help their husbands.

Omani culture has a significant influence on the attitude of its people towards leadership, having an impact on their efficiency and development of female leadership (Fathima and Venkoba, 2014). Culture shapes the way people think and perceive their lives. Women are made to believe that their role is at home taking care of their families instead of out there leading the society. The society perceives this as a role for men and therefore from a young age, men grow up knowing that they will be leading the community and organization. Thea cultural barriers that hinder women to reach leadership positions include family values where they are expected to stay at home.

\subsection{Research Problem}

The representation of women in the labor market varies from one country to another, depending on cultural, social and economic factors. However, in Arab countries, the participation rate of women in the workforce is the lowest in the world. In Oman, despite its current commitment to women's rights and empowerment, women occupy only $9 \%$ of the leadership positions among Omani civil service employees. Additionally, Oman is ranked 127 th out of 135 countries, and was given a 0.587 score, regarding the women participation in the labor market (National Center for Statistics and Information, 2011 cited in Kemp and Madsen, 2014). Indeed, it is challenging for women to reach leadership positions in all societies. International statistics indicated the existence of a gender gap in the distribution of leadership positions (Pfeifer, 2014). Omani women face many difficulties to take leadership positions even in the teaching fraternity despite the number of women in the society. The gap in the rate of women taken up careers as Principals is a problem that needs to be researched and solved.

There is a void for Omani women aspiring career advancement because of the lack of professional women's network. The absence of a positive female role-model relationship makes it difficult for women to develop the required attitudes, skills and abilities for leadership. It is not limited to the business field as even in the teaching world, women tend to settle for being teachers and do not seem to be aggressive to advancing their role into being principals. The conditions of both men and women are usually affected by the society rules which in turn, could have an impact on individuals' lives and their relationships (Duevel et al., 2015). Another 
significant obstacle to women's access to leadership positions is the society's perception of women as having weak qualities compared to men. If the members of a community look at women as being emotional and unable to make decisions, they detract women from being assessed as an employee in leading positions as these are essential characteristics of a leader. The general trend shows bias against women leaders, indicating that women who work in leadership positions are considered lacking with femininity (Duevel et al., 2015). In Oman, women still have challenges to earn what men make for the same job and to acquire the advancement that will place them in leadership roles.

\subsection{Objectives of the Study}

a. To investigate the barriers women faced in the appointment process and once in leadership positions at a Cycle 1 and Cycle 2 schools in Oman?

b. To discuss how women principals overcome the gender-related challenges emerging in their contexts?

\section{LITERATURE REVIEWS}

\subsection{Challenges on Leadership by Women}

\subsubsection{Cultural Challenges}

Although Oman is not an extremely conservative nation the women are still subject to their very traditional family role. Differences in the "supposed" role they are to play versus that of male are very clear. Perceptions of the male and female are embodied in law and custom (Al-Lamky, 2007). Furthermore, the rise of neo-traditionalist movements has further regressed women's opportunities since their values advocate seclusion and segregation of women. In Muscat, which is the capital city of Oman, women do not appear much in public gatherings such as the market. Women and men are traditionally not in a position to interact openly, and it is only in the confines of their home that this happens (Wikan, 1982). The fact that they have to avoid such public gatherings leaves them no choice but to keep of issues related to leadership as they would not be expected to stand before people. Some may feel that schools are a public gathering and therefore shy away from seeking education.

Wikam (1982) noted that men's world is far larger than that of women as what they are allowed to do far surpasses what a woman can do. Jones (2007) pointed out that even though social segregation may not be a reflection that women are inferior to men, it disadvantages the women as they may not be able to live up to their constitutional rights. Al-Jamali (2005) acknowledged the role of women in the political development in the Sultanate of Oman. The study highlighted that Omani women held jobs of managerial and leadership positions such as the Minister, Ambassador, Chancellor, and Expert. The study concluded by focusing on the developmental role of women and activating their participation in political, economic, education and social life. Women in Oman are desperately trying to fulfil a dual role. That of a modern, working, educated and enlightened woman, yet still trying to uphold 'the heavy weight of customs and traditions' (Al-Lamky, 2007). The findings of the study conducted by Kemp and Madsen (2014) revealed that, however, the literacy rate of females have improved considerably in the last 40 years.

However, Al-Barwani and Albeely (2007) declared that in Oman, the number of employed women is small when compared with the number of men. Currently, women remain extremely underrepresented in senior roles in Omani organizations, and there is only $30 \%$ of female involvement in the labor market (ILO, 2016).

\subsubsection{Appointment Process and Leadership Positions at Cycle 1 and Cycle 2}

In a study conducted in England by Coleman (2000), the majority of women principals felt that they had to prove their worth as a female principal. Coleman (2000) in his studies indicated that management and leadership often stereotype masculinity. Women often have to explain their leadership roles in the schools. There is a bias and a feeling that if they are married, they have to downplay their leadership roles for their motherhood and motherly duties (Coleman, 2000). They therefore tend to shy away from leadership roles as they feel this is not a priority for them.

Almost two-thirds of principals reported that they had found it an advantage to be a female principal (Coleman, 2000). In the Arab world it is not common that a woman joins leadership without starting a family. Indeed, the Arab family has an extremely strict and strong family unit. It is seen as "a secure and healthy environment for its members, guards against passions of whims and desires, and channels them to wholesome and meaningful pursuit" (Al-Barwani and Albeely, 2007). Especially in the rural areas, if a girl was to accept a position in another region, the endless moral and virtue problems she faces will make it almost impossible for her to do so. 'Women and girls have limited freedom of movement and their interactions are often limited to their own gender' (Al-Barwani and Albeely, 2007). If a principal however, is 
married and her husband does not work in the area she has been offered a position, it is very unlikely that she will be allowed to accept unless she will be able to travel to and from her school daily. Not only because she will experience some "challenges to balance between work and family such as the demands and responsibilities of her dual role as professional and homemaker' (Baran, 2013). But again her virtue and moral responsibility will be questioned.

\subsection{Gender Perception Challenges}

Duevel et al., (2015) stated that although women consider themselves equal to men, they value themselves as less effective compared to their men partners. A striking example of this is seen when men and women are offered a leadership positions, men are expressing high desire to take these positions. However, women hesitate till they find themselves ready for such positions. Kemp and Madsen (2014) found out that "Omani men value authority more than women do, because males have more direct involvement with authority figures". In fact, strong women in leadership positions are considered as aggressive and they are more disliked than women, on the contrary, strong men are usually seen as effective leaders (Duevel et al., 2015).

Albelushi (2004) highlighted that even though female education has increased, women in Oman tend to get married immediately after graduation and start having children. Women tend to change their view to life when they get children and they downplay their career growth to raising children. Albelushi (2004) indicated that even though women have the opportunity to pursue a career, they perceive their main role as that of taking care of the family. They even find themselves conflicted when the government policies encourage female participation in the public life as they still have a traditional mind-set.

\section{METHODOLOGY}

\subsection{Data Collection Method}

a. Study Sample: To address the research questions, I focused on thirty female school principals from different Cycle 1 and Cycle 2 schools in four different regions of Oman (Al Batina, Al Sharqia, Al Dakhalia and Al Dhahira).

b. The online questionnaires: An online questionnaire was designed through Google Form for primary data collection. I developed an online questionnaire to explore the obstacles that female school principals encountered on their own leadership pathways, on the appointment process and once in leadership positions at Cycle 1 and Cycle 2 schools in Oman. Also, how could female principals overcome the gender-related challenges emerging in their context?

The questionnaire consists of three parts. The first set of questions is aimed at determining the barriers that school principals encountered to reach this position. The final set of questions asks for some background information. I created open ended questions to maximize flow of information such as who discouraged you and why?

\subsection{Data analysis}

Once the data was collected through online questionnaires and online sources it was classified into various categories to form a conclusion as to whether the data made sense and was able to answer the research questions.. Tables, charts, and different themes to be able to show the challenges that women face in leadership were analyzed. Pseudonyms were used in the data analysis and writing up, where I used quotations from participants' responses to strengthen the findings. It therefore entailed looking at the responses given by the women principals in Oman and systematically breaking it down in a way that was comprehensive and easily understood.

Analysis of qualitative data entails defining and identifying the data, storing the data, reducing the data collected and finally coding the data (Coleman and Briggs, 2002). In this study the data was collected from a population of 30 participants, it was then categorized into various classes such as the duration that one has worked as a school principal, hours put in, their ages and how long it has taken to get to a supervisory level. The analysis of the answers received from the questionnaire will entail content analysis as the nature of research entails qualitative data. According to Coleman and Briggs (2002), when a questionnaire is issued, the researcher has a reason as to why they questions are asked, thereby, content analysis gives the opportunity to review the data provided to determine if anything was missed in the study.

\subsection{Validity, Reliability, Triangulation}

Reliability implies to the fact that results can be consistent over time and always provide consistent results. This means that when measurement is done on the same data over time, the results will be similar. 
Triangulation is meant to test the validity and reliability of the research that is conducted. It is highly advocated for as it strengthens a study (Golfashani, 2003). These were factors that were considered in this study to ensure that the results obtained from the research can be relied upon. Validity means that the research truly measures that which it is intended to measure. This, therefore, is implored in the accuracy of the results (Golfashani, 2003). Also, validity requires that the research measures and describes what was intended through the questionnaires (Coleman and Briggs, 2002).

\section{ANALYSIS OF FINDINGS}

\subsection{Challenges Based on Working}

Working as a woman means sacrificing time spent taking care of the family. With an average of fifteen working between 30-35 hours and twelve working for more than 35 hours means that they spend long periods of time in the schools. In addition, twenty two indicated that they have to do extra hours ranging from 5.5 hours up to 20 hours in a week. In Oman, although women take up the leadership roles, they still have to perform their family duties of taking care of the family. Thus, it implies that they are likely to have high level of exhaustion. Given the hours they are expected to be in school, resistance is likely to be received especially from the "husband" and the "fathers".

Moreover, in seeking education, women had to leave their children behind with their parents. They were expected to work hard and put in long hours of study. Once they got to the leadership roles, they were sometimes required to work far away from their homes and their children. It is expected that many women would not be willing to make such a sacrifice and especially in a family where there was another source of income. Therefore, they would be willing to sacrifice their careers in order to have more time for their families. The majority of the Omani female principals stated that it is difficult to pursue a career and especially in leadership compared to deciding to stay at home and take care of the family as the tradition expects. Despite these challenges, Omani female principals have gone ahead to further their studies and sought recruitment as principals but this has not been without its challenges.

\subsubsection{Barriers Women Faced in the Appointment Process and Once in Leadership Positions at Cycle 1 and Cycle 2 Schools in Oman}

The female school principals got their position through the central government of the Sultanate of Oman with only few get their position through internal promotions. One of the respondent indicated that they had to work for up to fifteen years in order to get the promotion and another worked for ten years before getting the promotion. The process towards getting the leadership position was termed as challenging as most had to work for an average of seven years as a teacher before advancing to a principal. The other route entailed pursuing further education and then applying through the central government to get to the position of a principal.

It is evident that through His Majesty Sultan Qaboos who has gradually regarded women as important partners of men in the development of the society and in agreement with the aims and objectives of United Nation's Millennium Development Goals, to promoting gender equality and women empowerment has endeavored to see that this is achieved by ensuring that more women get the role of principals when they apply for it (United Nations, 2008). This has led to the reason that most of the women principals in Oman got the position through the central government.

It is however a worrying trend those women take many years to get internal promotions. It is number of years that discourage the women to pursue leadership since they may get comfortable in their roles as teachers and may not want to take up additional challenges such as being principals.

\subsubsection{Barriers to Career Advancement}

In the analysis of the data that was collected through an online questionnaire, it is critical to highlight that the majority of responses (twenty five out of thirty respondents) felt that they did not have a specific barrier hindering them from advancing their career in the schools that they were leading. However, those that highlighted that there were barriers hindering them gave reasons such as 'high number of responsibilities'. They would like to do more to advance their career but this comes with the need to add more to their plate which they feel they cannot handle and thus opt to stay at their current status.

One of the principals asserted that 'there is no more space to grow upwards in the career and especially economically'. It is an internal factor that leads the principals frustrated in an effort to reach higher levels of leadership. It is in addition to the fact that for one to receive promotion, they have to receive training through the Directorate through nomination. It therefore limits the likelihood of internal growth. Nomination to the courses means seems biased and therefore limiting the ability for one to grow externally in their careers. 
Another hindrance that comes with being a woman is the fact that women do not always have the opportunity to travel to get the education to advance their career. The women principals have to consider factors such as leaving their children behind when pursuing further education as one principal stated that "I travelled to Australia to further my education and get my Master's degree. I have 3 kids at that time and I left them with my mother."

\subsection{Gender Based Challenges}

On collecting data to determine whether gender related challenges hindered women from pursuing their career, it was found out that their husbands and parents expect them to take care of the children. A number of school principals indicated that the husband and the father discouraged them because they are mothers and this job requires long hours of work. In addition, the study sought to find the perception that women principals have about themselves in leadership positions compared to the men.

When an inquisition was made as to whether women are viewed as inferior to men, the majority of participants (twenty six out of thirty) highlighted that this is not the case. However, the rest indicated that they feel women are viewed as inferior giving the reasons of that men feel that they are "better than women in leading".

It is important to note that a statistic of twenty six indicated that they do not think that women are inferior to men. It could be an indication that women are liberating themselves from the thought that they are inferior to men and they can actually lead. Thus, they are able to see themselves more than just mothers and wives and let go of the thought that they are inferior to men.

From the study we could see that the majority of female principals did not experience prejudice because they were women principals. Those who faced prejudice, because men felt they were better than women. Furthermore, nine participants stated that they faced barriers in the journey toward leadership and this was driven mainly by 'gender related issues'. One of the responses indicated that she faced gender related challenges. "Men believe that they are better leaders than women".

Furthermore, nine of the women principals felt that leading as women is harder as compared to leading as a man highlighting reasons such as 'men are flexible as compared to the woman who has to take care of the children and therefore they have more to accomplish in a day as compared to the men'. They also highlighted reasons such as 'making decisions on the varied issues that arise in the school requires a lot of wisdom'. This could be taken to indicate that women still feel that men are at a better position to make important decisions as compared to the men. However, it is obvious that women are putting an effort to overcome this barrier.

\subsection{Challenges Based on (Culture, Tradition and Family Barriers}

\subsubsection{Family Barriers}

Among the main challenges for the women principals that limited from pursuing a career was the family. In the survey conducted, the majority of participants (twenty three out of thirty) were not discouraged by their immediate family from pursuing a career. Six of the participants stated that they have been discouraged by the family with only one who highlighted such reasons as "My father and husband because I am a mother and this job require working for long hours". In reality, being a principal entails taking up extra responsibility. Husbands generally expect their wives to spend more time taking care of the children and the home.

Traditional way of thinking is still rampant in the Omani society. The data shows that parents are deemed to have the belief that women are meant to stay at home and take care of the family. Sara indicated that "Women are expected to be mothers, stay at home and take care of her kids".

Leaving the family for work or studies is a challenge that women principals have to encounter at some point in their career. For women, it is always anticipated that the children come firm. From the online questionnaire, one of the respondents who pursued further studies meant 'leaving her three children with her parents'. Additionally, working for long hours meant that the women would not be in a position to accomplish some of the tasks at homes.

\subsubsection{Cultural and Traditional Challenges}

Culture is a fundamental determinant to whether women seek leadership or not. It relates to the beliefs and values that are held by the people in the same community. Such culture includes the belief that women should stay at home, raise children and take care of their families. Therefore, in choosing a career and career advancement, they look at the implication that it will have on their cultural background. 


\subsection{How Do Women Principals Overcome the Gender-Related Challenges?}

Women are putting in an effort to overcome the gender barriers that they are faced with including showing the schools that they are actually the best by putting in extra hours, working harder and taking control of the roles that they are expected to accomplish. Hard work is seen as the key way through which they are trying to show that they are as good as the men. It is evident that women have to work harder than men. Other ways that women have been using to deal with gender related obstacles include seeking more education in order to advance their career. They stay enthusiastic on their jobs and keep believing in the obstacles that they face along the way. It is evident from the data collected that women are now more willing to overcome the barrier that have been placed along their paths in order to succeed as leaders.

\section{DISCUSSION}

\subsection{Barriers Women faced Once in Leadership Positions at a Cycle 1 and Cycle 2 Schools in Oman Cultural and Traditional Barriers to Leadership in Oman}

Studies have shown that traditions are culture hold back women towards looking to achieve success. However, women are showing signs of defying such cultures and seeking to be better in the society. They have refused to stay in their homes and just raise the children but have gone out of their way to seek education even outside their country. This has been drawn from the fact that women are seeking education outside Oman and coming back to seek promotions as principals. They have taken up additional responsibilities and are seen to be able to balance both roles effectively.

\subsection{Overcoming the Gender-Related Challenges in Oman}

Al-Lamky (2007) indicated that the ability of women to get appointment in position for which they participate in policy making has allowed women to evolve through male dominated country and move from being conservative to being an outspoken generation. In their studies Duevel et al (2015) highlighted those women leaders, indicating that women have worked to defy this trend by being able to run entire schools as principals. They are in a position to make strategic decisions for the schools, make annual plans and effectively deal with the challenges that come their way. They are seen to put extra effort in their work in order to prove that they are as good as the men in leadership positions. It is an indication that the women in Oman view themselves today with a better perspective in relation to men than in the past. The report further highlighted that the Omani women are actually resourcefully contributing towards economic development of the country.

In this study, a woman principal stated that though she was married early, she started schools and was able to go through schools and get into the teaching practice. She further pursued post graduate studies and managed to be appointed as a principal in a school. It is an indication of the spirit of resilience in the Omani women to refuse to just get married and settle to raising children. They are going beyond being held down by their status as women and the expectation that they should stay at home and take care of the children.

In his conclusion Miller (2014) noted that the Omani society is changing massively in order to empower women. Therefore, the culture that was upheld on the belief that women were meant to be housewives is changing. The society is therefore contributing towards ensuring that the new society has women who actually believe in their abilities and therefore molding a culture where it is normal for women to take up leadership. Also, the women in Oman are seen to embrace this concept by taking up roles not only as school principals but also in the political and economic sector.

\section{CONCLUSION}

A special emphasis was placed on how they overcome the gender related obstacles in their roles. Additionally, the study highlighted the perceptions that female school principals have with regards to their leadership positions. It also discussed how these principals looked into inspiring other aspiring women to join the leadership role as principal. Overall, the research was able to adequately address the research questions through the use of both primary and secondary data.

The barriers women faced in the appointment process and once in leadership positions at a Cycle 1 and Cycle 2 schools in Oman include lack of promotions, gender inequality and traditional barriers that believe that women should stay at home and take care of the children. Women in Oman have actually taken steps to overcome gender related barriers such as through pursuance of education within Oman and outside Oman. Finally, women Principal's perceptions about encouraging other teachers to take up a leadership role in Oman is very positive as they are seen to constantly encourage the teachers to take up leadership roles even on trial basis. 


\section{REFERENCE LIST}

Al-Barwani, T.A. and Albeely, T.S. (2007). The Omani family: strengths and challenges. Marriage \& Family Review, 41(1-2), pp.119-142.

Albelushi, A. (2004). Gender issues in teacher development: career choice and commitment in Oman. Engl Lang Teac Educat Develop, 8, pp.1-25.

Al-Jamali, F. (2005). The role of Women in the political development in the Sultanate of Oman, Twasel Magazine, Muscat, 3, 52-59.

Alkharusi, H., Aldhafri, S., Alnabhani, H. and Alkalbani, M. (2014). Modeling the relationship between gender. The Asia-Pacific Education Researcher, 23(1), pp.93-104.

Al-Omairi, T. and Amzat, I.H. (2012). Women in Omani Society: Education and Participation. OIDA International Journal of Sustainable Development, 3(5), pp.63-80.

Baran, H. (2013) The role of ethnic culture in work-family balance among Armenian women in leadership positions in higher education, Dissertation Abstracts International Section A, 73 (1), 11-A(E), PsycINFO, EBSCOhost.

Coleman, M. and Briggs, A. (2002). Research methods in educational leadership and management. London: P. Chapman Pub.

Coleman, J. (1966). Equality of educational opportunity [summary report], [Washington]: U.S. Dept. of Health, Education, and Welfare, Office of Education; [for sale by the Superintendent of Documents, U.S. Govt. Print. Off.].

Coleman, M. (2000). The female secondary head teacher in England and Wales: leadership and management styles. Educational Research, 42(1), pp.13-27.

Duevel, L., Nashman-Smith, M. and Stern, E. (2015). Moving from'womanless history'to women stepping up into school leadership roles. The International Schools Journal, 35(1), p.34.

Fathima, R. and Venkoba, R. (2014). Impact of national culture on the female leaders in Oman: An Empirical Study, Head, HR Services, Global Business Network LLC, Muscat, Oman, Professor, Majan University College, Muscat, Oman.

Golafshani, N. (2003). Understanding reliability and validity in qualitative research. The qualitative report, 8(4), pp.597-606.

ILO: International Labour Office. (2016). Meeting the employment challenge in the Sultanate of Oman. Sultanate of Oman: ILO Publications.

Jones, J. (2007). Negotiating change: The new politics of the Middle East (Vol. 58). IB Tauris.

Kemp, L.J. and Madsen, S.R. (2014). Oman's labour force: an analysis of gender in management. Equality, Diversity and Inclusion: An International Journal, 33(8), pp.789-805.

Miller, A. (2014). Are Women's Roles Changing in Oman?. The Student Researcher: A Phi Alpha Theta Publication. Paper 2. Available from: http://digitalcommons.wku.edu/stu res jour/2 [Accessed 29 July 2016].

Pfeifer, C. (2014). The Gender Composition of Establishments' Workforces and Gender Gaps in Wages and Leadership Positions. The Manchester School, 82(S2), pp.69-81.

Reciniello, S. (2011). Is Woman the Future of Man?: An Exploration of the Potential of Women in the Knowledge Economy and of the Problem of Gender Inequality in the Workplace. Organizational and Social Dynamics, 11(2), pp.151-174.

Schwanke, D.A. (2013). Barriers for women to positions of power: How societal and corporate structures, perceptions of leadership and discrimination restrict women's advancement to authority. Earth Common Journal, 3(2).

TOSD: Technical Office for Studies and Development. (2016). Ministry of Education, Sultanate of Oman.

United Nations (2008). Claiming the Millennium Development Goals. New York. United Nations.

Wikan, U. (1982). Behind the veil in Arabia. Baltimore: Johns Hopkins University Press. 